\title{
Richard P. Mcclary. Medieval Monuments of Central Asia. Qarakhanid Architecture of the 11th and 12th Centuries
}

\section{Viola Allegranzi}

\section{(2) OpenEdition Journals}

Édition électronique

URL : https://journals.openedition.org/abstractairanica/52722

DOI : 10.4000/abstractairanica.52722

ISSN : 1961-960X

Éditeur :

CNRS (UMR 7528 Mondes iraniens et indiens), Éditions de l'IFRI

\section{Référence électronique}

Viola Allegranzi, « Richard P. Mcclary. Medieval Monuments of Central Asia. Qarakhanid Architecture of the 11th and 12th Centuries ", Abstracta Iranica [En ligne], Volume 42-43| 2021, document 1, mis en ligne le 15 avril 2021, consulté le 13 décembre 2022. URL : http://journals.openedition.org/ abstractairanica/52722 ; DOI : https://doi.org/10.4000/abstractairanica.52722

Ce document a été généré automatiquement le 13 décembre 2022.

Tous droits réservés 


\title{
Richard P. Mcclary. Medieval Monuments of Central Asia. Qarakhanid Architecture of the 11th and 12th Centuries
}

\author{
Viola Allegranzi
}

\section{RÉFÉRENCE}

Richard P. Mcclary. Medieval Monuments of Central Asia. Qarakhanid Architecture of the 11th and 12th Centuries. Edinburgh: Edinburgh University Press, 2020, XX + 320 p., 244 ill.

(Edinburgh Studies in Islamic Art), ISBN: 978-1-4744-23977.

1 L'ouvrage rassemble le corpus des monuments attribuables à la confédération des Qarakhanides (389-609/999-1212), relevés dans les actuelles républiques centrasiatiques du Kazakhstan, Kirghizstan et Ouzbékistan (cf. Gazetteer, p. 311-315). Le mauvais état de conservation de la plupart de ces monuments - dont certains ont complétement disparu, tandis que d'autres ont été altérés par les reconstitutions récentes - empêche dans bien des cas de retracer de manière exhaustive leurs architecture et contexte d'origine. Face à ces limites, l'auteur s'efforce de rassembler les informations issues des publications précédentes, qui datent en majorité de l'époque soviétique et sont souvent peu accessibles, et de comparer les anciennes photographies des sites (dont plusieurs reproductions sont présentées au lecteur) avec des nouveaux relevés réalisés sur le terrain. Il observe également les rapports des monuments qarakhanides avec ceux - plus nombreux et mieux connus - attribués aux dynasties contemporaines des Ghaznavides, des Seldjoukides et des Ghourides (XI ${ }^{e}-\mathrm{XII}^{\mathrm{e}} \mathrm{s}$.), dispersés à travers le monde iranien et l'Anatolie. En portant son attention sur certains détails de l'exécution du décor architectural et des inscriptions, l'auteur parvient à identifier les quelques traits distinctifs d'un corpus qui reste de par sa nature très diversifié. Il s'attache encore à replacer l'architecture qarakhanide dans une tradition 
régionale, incarnée par les rares vestiges préservés de l'époque des Samanides (IX $\mathrm{X}^{\mathrm{e}} \mathrm{X}^{\mathrm{e}}$ s.), ainsi que par les réalisations postérieures commanditées par les Timourides (XIV ${ }^{e_{-}}$ $\mathrm{XV}^{\mathrm{e}}$ s.). Le volume, solidement construit et bien illustré, a l'indéniable mérite de redonner à un corpus architectural insuffisamment valorisé la place qu'il mérite. De plus, il attire l'attention sur certaines caractéristiques techniques et stylistiques qui ouvrent des perspectives nouvelles concernant l'évolution du répertoire formel de l'architecture, du décor architectural et de l'épigraphie monumentale dans le monde iranien pré-mongol.

\section{AUTEURS}

\section{VIOLA ALLEGRANZI}

Institut für Iranistik, ÖAW, Wien 